\title{
Assessing and restoring cognitive functions early after stroke
}

\author{
Chiara Zucchella, PsyD a,b \\ Annarita Capone, PsyD ${ }^{a}$ \\ Valentina Codella, PsyDa \\ Carmine Vecchione, MD ${ }^{c, d}$ \\ Giovanni Buccino, MD, PhDe \\ Giorgio Sandrini, MD \\ Francesco Pierelli, MDa, \\ Michelangelo Bartolo, MD, PhDa
}

a Neurorehabilitation Unit, IRCCS NEUROMED,
Pozzilli (Isernia), Italy
b Department of Brain and Behavioral Sciences,
University of Pavia, Italy
c Laboratory of Vascular Pathophysiology, IRCCS
NEUROMED, Pozzilli (Isernia), Italy
d Department of Medicine, University of Salerno,
Baronissi, Italy
e Department of Medical and Surgical Sciences,
Università Magna Graecia, Catanzaro, Italy
' Department of Neurological Rehabilitation, C.
Mondino National Neurological Institute, Pavia, Italy
g Department of Medico-Surgical Sciences and
Biotechnologies, "Sapienza" University of Rome, Italy

Correspondence to: Michelangelo Bartolo

E-mail: bartolomichelangelo@gmail.com

\section{Summary}

Cognitive impairment is a frequent complication of stroke. The aim of this study was to evaluate the effectiveness of cognitive training performed early after stroke.

Ninety-two patients were randomly assigned to either the study group (SG) or the control group (CG). Cognitive rehabilitation consisted of 16 individual one-hour sessions in which patients performed therapist-guided computer exercises. The patients in the CG performed a sham intervention. After four weeks all the patients were re-evaluated.

In the SG, significant improvements $(p<0.05)$ were detected in all neuropsychological measures at the post-training evaluation, while the CG showed mild (not statistically significant) improvements on cognitive tests. Between-group analysis revealed statisti- cally significant differences in the domains of memory and visual attention.

Cognitive training performed early after stroke seems to be a viable option for improving cognitive outcome in stroke survivors. Further studies should assess whether this may favor their reintegration into everyday life.

KEY WORDS: cerebrovascular disease, cognitive deficits, cognitive rehabilitation, neuropsychology, neurorehabilitation, stroke

\section{Introduction}

Impairment of cognitive functions is a possible complication of stroke, often being the predominant clinical feature (Ferro, 2001; Serrano et al., 2007). Approximately $74 \%$ of patients with cortical stroke, $46 \%$ of patients with subcortical stroke and $43 \%$ of patients with infratentorial stroke exhibit cognitive deficits, with a prevalence of executive and visual-perceptual dysfunctions (Nys et al., 2007) as well as of speech disturbances (Hoffmann, 2001).

Cognitive impairment can increase disability and indirectly affect functional recovery after stroke, as a result of reduced participation in rehabilitation and poor adherence to treatment guidelines (Cumming et al., 2013). Moreover, cognitive decline predicts poor recovery in activities of daily living (ADL), results in a reduced quality of life (Paolucci et al., 1996; Patel et al., 2003; Claesson et al., 2005; Hachinski, 2007; Daniel et al., 2009; Carod-Artal and Egido, 2009; Gialanella and Ferlucci, 2010; Paker et al., 2010), and is an independent predictor of institutionalization after stroke (Pasquini et al., 2007).

As reported in various neurological diseases (Sohlberg et al., 2000; Fasotti et al., 2000; O'Brien et al., 2008; Gehring et al., 2009; Zucchella et al., 2013; Cerasa et al., 2013), cognitive rehabilitation, involving training in and/or teaching of compensatory strategies, with the ultimate aim of fostering positive adaptation to the environment (Ladavas et al., 2011; Cha and Kim, 2013), seems to constitute a valuable therapeutic option for improving patients' cognitive performances. However, partly due to the heterogeneity of poststroke cognitive impairments, the evidence regarding treatments in this area is still unclear or inconsistent: cognitive rehabilitation has not yet become part of standard practice and several issues (e.g. type, tim- 
ing, duration and intensity of interventions, and outcome measures) remain open (Nair and Lincoln 2007; Cicerone et al., 2011; Bowen et al., 2013; Loetscher and Lincoln, 2013; Chung et al., 2013). At present, there are no clinical tools or guidelines available to address post-stroke cognitive rehabilitation across all cognitive domains (Taylor and Broomfield, 2013); however, in recent years, a number of experimental and meta-analysis studies have indicated some effectiveness of cognitive rehabilitation programs in reducing the consequences of executive impairments (Poulin et al., 2012).

Moreover, while there is evidence that motor rehabilitation after stroke should be started as early as possible, namely when the impact of the treatment is potentially greater (Adams et al., 2003; Quinn et al., 2009; Wang et al., 2011; Bernhardt et al., 2013; Brauer et al., 2013), only a few studies have addressed early cognitive rehabilitation after stroke (Johansson, 2011). A recent study produced preliminary data supporting the beneficial effects of early (performed within two weeks of stroke) cognitive training based on the use of computer programs for correcting impairments in attention and visuospatial abilities (Prokopenko et al., 2013). In view of these positive results, the same authors stressed the need to develop further studies to elucidate the whole spectrum of rehabilitation opportunities offered by this approach.

The present study was conducted to assess whether a comprehensive cognitive rehabilitation program, combining computer training and metacognitive strategies, may improve the cognitive outcome of stroke inpatients. This report provides details about the timing and mode of delivery of the intervention.

\section{Materials and methods}

\section{Participants}

The study enrolled consecutive patients referred to our neurorehabilitation unit between $1^{\text {st }}$ June 2010 and $31^{\text {st }}$ December 2012. The inclusion criteria were: first-ever ischemic or hemorrhagic (not evacuated) stroke confirmed by neuroimaging (computed tomography, CT or magnetic resonance, MR); acute event within the previous four weeks; age between 45 and 80 years; MiniMental State Examination (MMSE) score > 10; cognitive deficits, defined as test scores below populationbased norms, on at least three neuropsychological tests at the baseline evaluation. The exclusion criteria were: progressing stroke; neglect; aphasia; additional neurological or psychiatric disorders; Hamilton Depression Rating Scale (HDRS) score > 7; premorbid IQ score $<70$ or pre-existing dementia; visual deficits; motor impairment liable to affect the patient's performance on some tests.

All the patients gave their written informed consent to take part in the study. The study was approved by the local ethics committee and was conducted in accordance with the revised version of the Helsinki Declaration.

\section{Study design and procedures}

On admission, all the patients underwent a complete clinical and neurological examination performed by a neurologist or physiatrist with specific experience in neurorehabilitation. The severity of neurological impairment was measured by means of the National Institutes of Health (NIH) Stroke Scale (Brott et al., 1989), while the functional evaluation was based on the Functional Independence Measure (FIM) (Hamilton et al., 1987).

The baseline neuropsychological assessment was performed within the first week of admission (T0). Patients who met the inclusion criteria were enrolled in the study and randomly assigned to the study group (SG) or to the control group (CG) by means of a computer random number generator.

The patients in the SG performed cognitive training while those in the CG spent the same amount of time with a psychologist, discussing general topics, news, and their recent activities.

The patients in both groups (SG, CG) were re-evaluated after four weeks (T1) and gave a score indicating their level of satisfaction with the therapy $(1=$ poor; $2=$ sufficient; 3 =good; 4=excellent). All the assessments were done by a psychologist blind to the patients' randomization and not involved in their care. All the patients received usual rehabilitation care (medications, physiotherapy) and the two groups were comparable in the distribution of therapies and daily schedule.

\section{Neuropsychological assessment}

The neuropsychological evaluation assessed various cognitive domains: verbal and spatial immediate memory span (Digit Span and Corsi's Test) (Orsini et al., 1987), episodic memory, immediate and delayed recall (Rey Auditory Verbal Learning Test-RAVLT) (Carlesimo et al., 1996), logical memory, immediate and delayed recall (Carlesimo et al., 2002), non-verbal reasoning (Raven's Colored Progressive Matrices 47-PM47) (Basso et al., 1987), frontal functionality (Frontal Assessment Battery, FAB) (Apollonio et al., 2005), simple speed processing and complex attention (Trail Making Test A, TMT-A and Trail Making Test B, TMT-B, respectively) (Giovagnoli et al., 1996), visual selective attention (Attentive Matrices) (Spinnler and Tognoni, 1987), verbal fluency, both phonological and semantic (Novelli et al., 1986), visual-constructive abilities (ReyOsterrieth Complex Figure, copy) (Caffarra et al., 2002), global cognitive functioning (MMSE) (Folstein et al., 1975), and language (Aachener Aphasie Test, AAT) (Luzzatti et al., 1996). Parallel versions of the RAVLT were used at follow-up assessments.

Mood was assessed by means of the HDRS (Hamilton, 1960).

The tests were selected bearing in mind that neuropsychological protocols must be sensitive to a wide range of abilities and that the use of brief mental status scales alone may result in under-representation of mild and specific cognitive deficits, being inadequate 
for documenting post-stroke neuropsychological sequelae (Hachinski et al., 2006).

\section{Cognitive training}

The standardized cognitive rehabilitation program consisted of 16 hours of individual training, divided into one-hour sessions spread over four weeks (four sessions per week). This training was administered by two psychologists, both experts in neuropsychology. The sessions included 45 minutes of therapist-guided computer exercises using two software programs: "Una palestra per la mente" (Gollin, 2011) and "Training di riabilitazione cognitiva" (Powell and Malia, 2009).

The exercises varied in content and addressed different cognitive domains, as detailed below:

- Time orientation: days of the week, months of the year, seasons, holidays and celebrations; anagrams of the days of the week, months and seasons; identification of temporal sequences within a story or in the execution of $A D L$; temporal sequences with images relating to $A D L$; - Spatial orientation: recognition of right and left; recognition and identification of cities, regions; word search puzzles; positions of objects; observation of scenes and identification of the position of objects; orienteering skills following pathways;

- Visual attention: searching for targets among distractors (stylized elements or objects); word search puzzles; finding the differences between images/scenes; searching for elements by categories;

- Logical reasoning: calculation; words in context; searching for intruders within categories; logical completion (metaphors and proverbs); categorization;

- Memory: recognition of pairs of words with or without logical connections; remembering lists; face recognition; memorization of scenes and stories then answering a questionnaire; object location and object seeking (e.g. memory game with cards).

- Executive functions: answering questions about a story; identifying the purpose/meaning of a story; following pathways subject to certain rules; recognition of moods; mathematical logic; action planning; re-ordering the sequence of a story; critical judgment (giving the pros and cons of ethical and social topics); problem solving.

Each exercise had increasing levels of difficulty (from level 1 to level 3); the transition to a higher level of difficulty occurred when the patient was able to perform the exercise with a $70 \%$ correct response rate. If a patient was unable, in three attempts, to resolve an exercise, the presentation was simplified and, through examples, made more understandable.

As the patients performed the exercises, the psychologist suggested metacognitive strategies to them in order to develop their awareness and self-regulation (e.g. the psychologist asked patients to predict their results on specific tasks, monitor and evaluate their performance, identify factors contributing to failures and successes). During the last 15 minutes of the session, the psychologist reasoned with the patients about any problems encountered in performing the exercises, explaining how to transfer the learned strategies to everyday situations in order to foster their generalization to realworld tasks (e.g. patients were encouraged to adopt "associative techniques" and to use their imagination to improve their memory: "To avoid forgetting your keys when you leave the house, always stop for a moment (at least $10 \mathrm{sec}$ ) to imagine and visualize the keys inside your bag. This association will become automatic and as a result you will easily remember the keys whenever you get your bag)". To ensure intertherapist reliability, also so that the patients received the same guidance during the training sessions, the psychologists followed written instructions and examples defined during the drafting of the protocol.

\section{Statistical analysis}

All the clinical variables were analyzed using descriptive statistics; median values and the $25^{\text {th }}$ and $75^{\text {th }}$ quartiles were found for all the non-parametric variables. The Mann-Whitney $U$ test and the chi-square test were used to compare demographic and baseline clinical and neuropsychological features between the two groups of patients.

For neuropsychological measures, age-, gender- and education-corrected scores were calculated from the raw scores according to Italian population-based norms and only corrected scores were included in the statistical analysis.

Changes within groups were investigated using the Wilcoxon signed-rank test.

Comparisons of outcome measures (neuropsychological test scores at T1) between the two groups were performed using the Mann-Whitney $U$ test.

Non-parametric statistics were applied as the ShapiroWilk test revealed that the data were not normally distributed.

Statistical analysis was performed using the Statistical Package for the Social Sciences version 17.0 for Windows (SPSS Inc., Chicago, IL, USA). The level of significance was set at $p \leq 0.05$.

\section{Results}

Of 288 stroke survivors admitted to our neurorehabilitation unit, 92 met the inclusion criteria and were randomly assigned to the SG $(n=45)$ and CG $(n=47)$.

Figure 1 shows the flow of participants through the trial. Three members of the SG dropped out because of poor compliance $(n=1)$ or worsening of their clinical conditions $(n=2)$. In the $C G$, two patients were not reevaluated at $\mathrm{T} 1$ due to their poor clinical conditions. Therefore the final statistical analysis was performed on 42 SG patients and 45 CG patients.

Comparison, between the two groups, of their sociodemographic, clinical and functional features on admission (TO) revealed no significant differences, suggesting that the two groups were matched (Table I). Moreover, there were no significant differences 


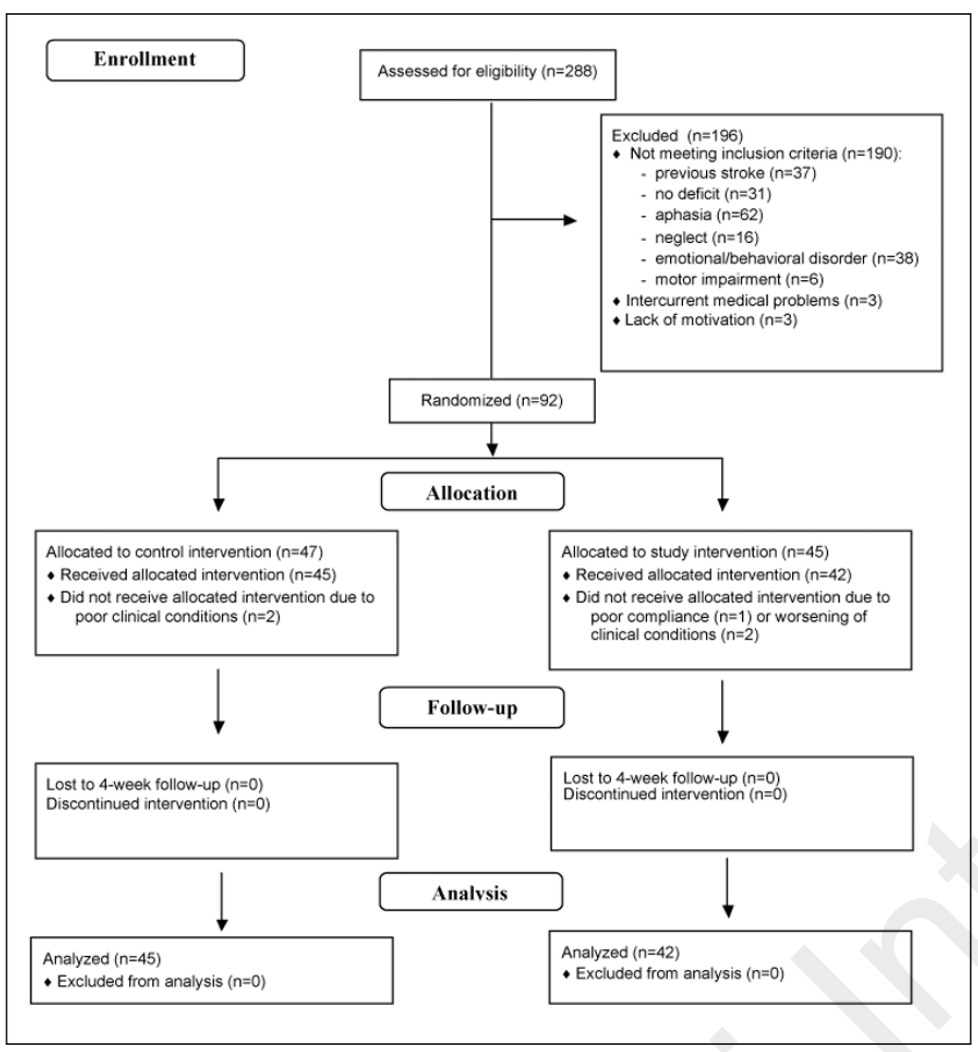

Figure 1 - CONSORT flow chart of patient participation.

Table I - Demographic and clinical features.

\begin{tabular}{|c|c|c|c|}
\hline & & Study group $(n=42)$ & Control group $(n=45)$ \\
\hline & $\begin{array}{l}\text { Age in years }\left[25^{\text {th }} ; 75^{\text {th }} \text { quartiles] }\right. \\
\text { Education (yrs) }\end{array}$ & $\begin{array}{l}64[56.2 ; 74.2] \\
8[5 ; 13]\end{array}$ & $\begin{array}{l}70[62.5 ; 76.5] \\
8[4.5 ; 11]\end{array}$ \\
\hline Gender & $\begin{array}{l}\text { Female } n(\%) \\
\text { Male } n(\%)\end{array}$ & $\begin{array}{l}19(45.2) \\
23(54.8)\end{array}$ & $\begin{array}{l}22(48.9) \\
23(51.1)\end{array}$ \\
\hline Comorbidities & $\begin{array}{l}\text { Diabetes mellitus, } n(\%) \\
\text { Hypertension, } n(\%) \\
\text { Heart disease, } n(\%) \\
\text { Atrial fibrillation, } n(\%) \\
\text { Hypercholesterolemia, } n(\%) \\
\text { Current smoker, } n(\%)\end{array}$ & $\begin{array}{l}9(21.4) \\
32(76.1) \\
7(16.7) \\
8(19) \\
23(54.7) \\
14(33.3)\end{array}$ & $\begin{array}{l}9(20) \\
31(68.9) \\
8(17.8) \\
5(11.1) \\
28(62.2) \\
17(37.8)\end{array}$ \\
\hline \multicolumn{4}{|c|}{ Stroke-related characteristics } \\
\hline Stroke type & $\begin{array}{l}\text { Ischemic, } n(\%) \\
\text { Hemorrhagic, } n(\%)\end{array}$ & $\begin{array}{l}31(73.8) \\
11(26.2)\end{array}$ & $\begin{array}{l}34(75.6) \\
11(24.4)\end{array}$ \\
\hline Lesion location & $\begin{array}{l}\text { Left hemisphere, } n(\%) \\
\text { Right hemisphere, } n(\%) \\
\text { Bilateral, } n(\%) \\
\text { Brain stem, } n(\%) \\
\text { Cerebellum, } n(\%)\end{array}$ & $\begin{array}{l}12(28.6) \\
18(42.9) \\
1(2.4) \\
8(19) \\
3(7.1)\end{array}$ & $\begin{array}{l}14(31.1) \\
27(60) \\
1(2.2) \\
3(6.7) \\
0\end{array}$ \\
\hline Lesion site & $\begin{array}{l}\text { Cortical, } n(\%) \\
\text { Subcortical, } n(\%) \\
\text { Infratentorial, } n(\%)\end{array}$ & $\begin{array}{l}20(47.6) \\
19(45.2) \\
3(7.2)\end{array}$ & $\begin{array}{l}25(55.6) \\
20(44.4) \\
0\end{array}$ \\
\hline Bamford Classification & $\begin{array}{l}\text { TACS } n(\%) \\
\text { PACS } n(\%) \\
\text { POCS } n(\%) \\
\text { Time for admission } \\
\text { FIM } \\
\text { NIHSS }\end{array}$ & $\begin{array}{l}12(28.6) \\
17(40.5) \\
13(30.9) \\
11.5[10 ; 14] \\
39.5[28 ; 48] \\
15[14 ; 17]\end{array}$ & $\begin{array}{l}13(28.9) \\
21(46.7) \\
11(24.4) \\
11[9 ; 14] \\
38[32.5 ; 49] \\
15[13 ; 15.2]\end{array}$ \\
\hline
\end{tabular}

Abbreviations: TACS=total anterior circulation stroke; PACS=partial anterior circulation syndrome; $P O C S=$ posterior circulation syndrome. FIM=Functional Independence Measure; NIHSS=National Institutes of Health $(\mathrm{NIH})$ Stroke Scale. ${ }^{*} p<0.05$. The $25^{\text {th }}$ and the $75^{\text {th }}$ quartiles are given in square brackets. 
between the two groups in any of the neuropsychological test scores (all $p$ values $\geq 0.05$ ).

At T1 (post-training/four weeks) the within-group analysis showed statistically significant improvements in all neuropsychological measures in the SG, while the CG showed only a trend towards improvements, as indicated by the enhanced corrected scores on the cognitive tests, which however did not reach statistical significance (Table II).

The comparison between the SG and the CG at T1 revealed significant differences in the domains of visual attention and verbal memory, in favor of the SG. The data are summarized in Table III.

Both the SG and the CG showed a statistically significant improvement in functional status between TO and T1 $(p=0.000)$ (Table II), with no statistical differences found between the groups at T1 (Table III).

The satisfaction score $(\operatorname{mean} \pm S D)$ was significantly higher in the $S G(3.19 \pm 0.45)$ than in the CG $(2.57 \pm 0.62)(p=0.000)$.

\section{Discussion}

The results of this randomized controlled study show that cognitive training performed in the first weeks after stroke is effective in inducing improvements in cognitive functions: both groups showed improved cognitive performance, but the post-treatment assessment was significantly different from the baseline one only in the SG.

Moreover, when comparing the two groups, considerable improvements in the domains of visual attention and verbal memory were evident only in the SG.

The early implementation of cognitive intervention, i.e. during the subacute phase, is a novel aspect of this work: indeed, although early bedside cognitive assessment is possible in most stroke patients (Hoffmann et al., 2009), in clinical practice, the implementation of specific cognitive rehabilitation is often neglected in the early stage after stroke (Johansson, 2011). In fact, in order to avoid the confounding effect of spontaneous recovery (Kwakkel et al., 2006), most studies in the rehabilitation field involve chronic patients, even though optimal benefits are likely to be obtained in the subacute phase of stroke as shown in relation to motor outcome in stroke units (Dewey et al., 2007; Johansson, 2011). The adaptive capacity of the human brain is supposed to be greater soon after brain damage and might help neural circuits that have been spared or less affected by a disease to compensate for the deteriorated circuits and improve the performance of other networks and overall neurological function (Palop et al., 2006). In this phase rehabilitation seeks

Table II - Baseline and four-week outcome measures (within-group analysis).

\begin{tabular}{|c|c|c|c|c|c|c|}
\hline \multirow[b]{2}{*}{ Outcome measures } & \multicolumn{2}{|c|}{ Study group } & \multicolumn{3}{|c|}{ Control group } & \multirow[b]{2}{*}{$\mathrm{p}$} \\
\hline & Baseline & 4 weeks & $\mathrm{p}$ & Baseline & 4 weeks & \\
\hline MMSE & $22.8[19.2 ; 26.3]$ & $25.4[21 ; 27.7]$ & 0.000 & 21.9 [18.2; 26.4] & $23.2[18.1 ; 26.6]$ & n.s. \\
\hline Digit Span & $4.2[3.6 ; 4.7]$ & $4.5[4.2 ; 5]$ & 0.001 & $4.5[4 ; 4.7]$ & $4.5[4 ; 4.7]$ & n.s. \\
\hline Corsi's Test & $3.7[3 ; 4.3]$ & $4.2[3.7 ; 4.7]$ & 0.000 & $4[3.4 ; 4.7]$ & $4[3.5 ; 4.7]$ & n.s. \\
\hline $\begin{array}{l}\text { RAVLT - immediate } \\
\text { recall }\end{array}$ & $22.6[17.6 ; 34.1]$ & 30 [22.3; 40.1] & 0.000 & 29.5 [20.8; 37.5] & $27.2[23 ; 33.4]$ & n.s. \\
\hline $\begin{array}{l}\text { RAVLT - delayed } \\
\text { recall }\end{array}$ & $3.9[3.2 ; 6]$ & $7.2[5.1 ; 8.5]$ & 0.000 & $4.7[3.2 ; 6.1]$ & $3.9[3.4 ; 5.8]$ & n.s. \\
\hline $\begin{array}{l}\text { Logical memory - } \\
\text { immediate recall }\end{array}$ & $3[2 ; 4.9]$ & $4.5[3.4 ; 6]$ & 0.000 & $3.5[2.4 ; 4]$ & $3.4[2.6 ; 4.6]$ & n.s. \\
\hline $\begin{array}{l}\text { Logical memory - } \\
\text { delayed recall }\end{array}$ & $2.2[1.1 ; 5]$ & $4.4[3 ; 6]$ & 0.000 & $3.2[1.5 ; 3.9]$ & $3.2[1.8 ; 4.4]$ & n.s. \\
\hline PM47 & $21.5[17.8 ; 24.7]$ & $23.3[18.3 ; 29.1]$ & 0.000 & $20.5[16 ; 24.7]$ & $22.5[16.5 ; 25]$ & n.s. \\
\hline FAB & $13.1[11 ; 14.5]$ & $13.9[12.5 ; 14.9]$ & 0.023 & $13.7[12 ; 14.3]$ & $13.8[12.3 ; 14.3]$ & n.s. \\
\hline TMT-A & $116[80 ; 156]$ & $91[58.5 ; 116]$ & 0.000 & $112[99.2 ; 135.7]$ & $110[95 ; 129.2]$ & n.s. \\
\hline TMT-B & 299 [215.5; 375] & 259 [158; 338] & 0.005 & 320.5 [246.5; 359.7] & 318 [239.2; 379.2] & n.s. \\
\hline Attentive Matrices & $21.8[13.5 ; 31.7]$ & $31.3[22.2 ; 40.5]$ & 0.000 & 23.7 [20.7; 28.9] & 24.7 [19.9; 30.7] & n.s. \\
\hline Phonological fluency & $18[13 ; 24.5]$ & 21.5 [14.3; 28.5] & 0.000 & $20[16 ; 24]$ & $21[17 ; 23.5]$ & n.s. \\
\hline Semantic fluency & $23[18 ; 32]$ & $30[22.5 ; 37.7]$ & 0.000 & $26[21 ; 33]$ & $27[24.5 ; 34.5]$ & n.s. \\
\hline $\begin{array}{l}\text { Rey-Osterrieth Figure, } \\
\text { copy }\end{array}$ & $15.6[12 ; 24.4]$ & $21.1[13.4 ; 30.7]$ & 0.000 & $14.4[12.6 ; 22.8]$ & $15.5[12.2 ; 23.7]$ & n.s. \\
\hline FIM & $39.5[28 ; 48]$ & $72[58 ; 99]$ & 0.000 & 38 [32.5; 49] & $74[66 ; 84]$ & 0.000 \\
\hline
\end{tabular}

Abbreviations: MMSE=Mini-Mental State Examination; RAVLT=Rey Auditory Verbal Learning Test; PM47=Progressive Matrices 47; FAB=Frontal Assessment Battery; TMT-A=Trail Making Test Part A; TMT-B=Trail Making Test Part B; FIM=Functional Independence Measure. $p \leq 0.05 ; n . s .=n o t ~ s i g n i f-$ icant. The $25^{\text {th }}$ and the $75^{\text {th }}$ quartiles are given in square brackets. 
to accompany and facilitate this spontaneous intrinsic recovery, strengthening it and removing factors that may hinder it or slow it down (Kwakkel et al., 2006). The improvement in cognitive functions observed in the SG, most evident in the attentional and mnestic domains, could be explained on the basis of the "retraining" approach used in this study.

The retraining method is in fact based on the assumption that a "target process" can be enhanced by repetitive stimulation, in the form of frequently practiced exercises for example (Petersen et al., 1998); such repetition is thought to make the skill more automatic and might induce a restitution of function in the brain, through modification of synaptic connectivity (Sturm et al., 2004; Kim et al., 2009).

Rehabilitation in mild cognitive impairment is usually based on the retraining method, which demonstrates positive effects particularly in the domain of attention, as seen in the patients observed in this study; instead, when deficits are more severe, the teaching of compensatory strategies seems to be more suitable (Robertson and Murre, 1999).

This latter approach might have favored a strengthening of the logical-executive functions, addressing the practical implications of cognitive deficits by exploiting the patients' residual intact cognitive abilities. It is hoped that future studies will combine these two approaches, identifying the specific characteristics of each, as well as effective integration methods to exploit the strengths of both.

The CG, too, showed a positive trend on the neuropsychological tests, although the differences versus baseline did not reach statistical significance. These improvements could be due to spontaneous recovery and/or to non-specific factors related to the intervention per se, such as the "the whole care experience" or the "therapeutic relationship", and thus substantiate the added value of the specific and structured rehabilitation training performed by the SG, which produced a greater cognitive gain. In the structuring of the rehabilitation sessions, considerable attention was paid to including moments during which patients could reflect on the activities and receive feedback on their work, with the aim of reorienting or reinforcing their behaviors. In the first case, the feedback served to identify behaviors that did not contribute to the goals, inducing the patients to develop alternative strategies or solutions. In the second case, in which it served to highlight useful and appropriate behaviors for achieving the goal, the feedback stimulated the patients to repeat and improve them.

Compliance with the program was generally high, even among the older patients less familiar with computers; the computer interface was very simple and user-friendly and, instead of being a limiting factor, might have made the treatment more pleasant and motivating for the patients, as suggested by the satisfaction score which was significantly higher in the SG. This finding raises the issue of the best age for cognitive training, and also offers pointers regarding types of patients who may not immediately seem suitable candidates for neuropsychological rehabilitation but who could in fact derive benefits from it.

As regards the patients' functional recovery, our findings showed that both groups obtained a significant functional gain, regardless of cognitive training. Indeed, FIM total scores at discharge were higher in the SG and in

Table III - Post-intervention outcome measure (between-group analysis).

\begin{tabular}{llll}
\hline Outcome measures & Study group & Control group & $p$ \\
\hline MMSE & $25.4[21 ; 27.7]$ & $23.2[18.1 ; 26.6]$ & 0.05 \\
Digit Span & $4.5[4.2 ; 5]$ & $4.5[4 ; 4.7]$ & n.s. \\
Corsi's test & $4.2[3.7 ; 4.7]$ & $4[3.5 ; 4.7]$ & n.s. \\
RAVLT - immediate recall & $30[22.3 ; 40.1]$ & $27.2[23 ; 33.4]$ & n.s. \\
RAVLT - delayed recall & $7.2[5.1 ; 8.5]$ & $3.9[3.4 ; 5.8]$ & 0.000 \\
Logical memory - immediate recall & $4.5[3.4 ; 6]$ & $3.4[2.6 ; 4.6]$ & 0.005 \\
Logical memory - delayed recall & $4.4[3 ; 6]$ & $3.2[1.8 ; 4.4]$ & 0.009 \\
PM47 & $23.3[18.3 ; 29.1]$ & $22.5[16.5 ; 25]$ & n.s. \\
FAB & $13.9[12.5 ; 14.9]$ & $13.8[12.3 ; 14.3]$ & n.s. \\
TMT-A & $91[58.5 ; 116]$ & $110[95 ; 129.2]$ & 0.01 \\
TMT-B & $259[158 ; 338]$ & $318[239.2 ; 379.2]$ & 0.03 \\
Attentive Matrices & $31.3[22.2 ; 40.5]$ & $24.7[19.9 ; 30.7]$ & 0.01 \\
Phonological fluency & $21.5[14.3 ; 28.5]$ & $21[17 ; 23.5]$ & n.s. \\
Semantic fluency & $30[22.5 ; 37.7]$ & $27[24.5 ; 34.5]$ & n.s. \\
Rey-Osterrieth Figure, copy & $21.1[13.4 ; 30.7]$ & $15.5[12.2 ; 23.7]$ & n.s. \\
FIM & $72[58 ; 99]$ & $74[66 ; 84]$ & n.s. \\
\hline Abevi & & \\
\hline
\end{tabular}

Abbreviations:MMSE=Mini-Mental State Examination; RAVLT=Rey Auditory Verbal Learning Test; PM47=Progressive Matrices 47; FAB=Frontal Assessment Battery; TMT-A=Trail Making Test Part A; TMT-B=Trail Making Test Part B; FIM=Functional Independence Measure. $\mathrm{p} \leq 0.05$; n.s. $=$ not significant. The $25^{\text {th }}$ and the $75^{\text {th }}$ quartiles are given in square brackets. 
our opinion, the lack of statistical significance in the between-groups analysis could be explained by the small sample size. Preliminary evidence from the literature in fact suggests that cognitive impairment can increase disability and indirectly affect functional recovery after stroke, as a result of reduced participation in rehabilitation and poor adherence to treatment guidelines (Cumming et al., 2013). Studies on larger populations will confirm the hypothesis that cognitive enhancement can impact on functional recovery.

Some possible limitations of the study should be underlined. First of all, we are aware that, as regards most of the neuropsychological tests, four weeks is a short interval to wait before re-testing, and a learning effect cannot be excluded; however, in our opinion, the use of a CG can control for this effect.

At present, no follow-up data are available. Data from longitudinal six-month assessments, including cognitive tests and scales for assessing ADL, are being collected to test the transfer of learned skills to daily life after discharge and to determine whether the positive results are maintained over time.

Moreover, these results can be generalized only to patients suffering from mild cognitive impairments, similar to the group studied, and who have residual cognitive resources and sufficient motivation to follow the rehabilitation program; further studies are needed to verify the feasibility of this intervention in patients presenting more severe cognitive deficits and to detect which specific patient features predict responsiveness to cognitive rehabilitation.

Finally, quality of life (QoL) assessment was not performed. QoL in stroke patients is a multidimensional concept that encompasses not only physical, but also psychological, emotional and social components associated with the illness (Owolabi, 2010; Carod-Artal, 2012). In our opinion these fundamental aspects could not be captured adequately by an investigation conducted in the acute phase of hospitalization, as ours was.

As cognitive function is increasingly regarded as an important endpoint in neurological patients, neuropsychological rehabilitation seems to constitute a valuable therapeutic option to improve cognitive performances. Although we evaluated this training only in stroke patients, in our opinion, the contents of this program can be used whenever a cognitive impairment is present, regardless of the underlying neurological disease. Future trials are needed to clearly identify the most effective elements in rehabilitation programs, to assess the characteristics of patients who may benefit from cognitive rehabilitation, and to determine how to transfer and possibly maintain, in daily life, the positive effects derived from it.

\section{References}

1) Adams HJ Jr, Adams RJ, Brott T, et al (2003). Guidelines for the early management of patients with ischemic stroke: a scientific statement from the stroke council of the American Stroke Association. Stroke 34:1056-1083.

2) Apollonio I, Leone M, Isella V, et al (2005). The Frontal
Assessment Battery (FAB): normative values in an Italian population sample. Neurol Sci 26:108-116.

3) Basso A, Capitani E, Laiacona M (1987). Raven's coloured progressive matrices: normative values in 305 adult normal controls. Funct Neurol 2:189-194.

4) Bernhardt J, Indredavik B, Langhorne $P$ (2013). When should rehabilitation begin after stroke? Int J Stroke 8:5-7.

5) Bowen A, Hazelton C, Pollock A, et al (2013). Cognitive rehabilitation for spatial neglect following stroke. Cochrane Database Syst Rev 7:CD003586.

6) Brauer SG, Hayward KS, Carson RG, et al (2013). The efficacy of SMART Arm training early after stroke for stroke survivors with severe upper limb disability: a protocol for a randomised controlled trial. BMC Neurol 13:71.

7) Brott T, Adams HP Jr, Olinger CP, et al (1989). Measurements of acute cerebral infarction: a clinical examination scale. Stroke 20:864-870.

8) Caffarra P, Vezzadini G, Dieci F, et al (2002). ReyOsterrieth complex figure: normative values in an Italian population sample. Neurol Sci 22:443-447.

9) Carlesimo GA, Buccione I, Fadda L, et al (2002). Standardizzazione di due test di memoria per uso clinico: Breve Racconto e Figura di Rey. Nuova Rivista di Neurologia 12:1-13.

10) Carlesimo GA, Caltagirone C, Gainotti G (1996). The Mental Deterioration Battery: normative data, diagnostic reliability and qualitative analyses of cognitive impairment. The Group for the Standardization of the Mental Deterioration Battery. Eur Neurol 36:378-384.

11) Carod-Artal FJ, Egido JA (2009). Quality of life after stroke: the importance of a good recovery. Cerebrovasc Dis 27 (Suppl 1):204-214.

12) Carod-Artal FJ (2012). Determining quality of life in stroke survivors. Expert Rev Pharmacoecon Outcomes Res 12:199-211.

13) Cerasa A, Gioia MC, Valentino $P$, et al (2013). Computerassisted cognitive rehabilitation of attention deficits for multiple sclerosis: a randomized trial with fMRI correlates. Neurorehabil Neural Repair 27:284-295.

14) Cha YJ, Kim H (2013). Effect of computer-based cognitive rehabilitation $(\mathrm{CBCR})$ for people with stroke: a systematic review and meta-analysis. NeuroRehabilitation 32 :359-368.

15) Chung CS, Pollock A, Campbell T, et al (2013). Cognitive rehabilitation for executive dysfunction in adults with stroke or other adult non-progressive acquired brain damage. Cochrane Database Syst Rev 4:CD008391.

16) Cicerone KD, Langenbahn DM, Braden C, et al (2011). Evidence-based cognitive rehabilitation: updated review of the literature from 2003 through 2008. Arch Phys Med Rehabil 92:519-530.

17) Claesson L, Lindén T, Skoog I, et al (2005). Cognitive impairment after stroke - impact on activities of daily living and costs of care for elderly people. The Göteborg 70+ Stroke Study. Cerebrovasc Dis 19:102-109.

18) Cumming TB, Marshall RS, Lazar RM (2013). Stroke, cognitive deficits, and rehabilitation: still an incomplete picture. Int J Stroke 8:38-45.

19) Daniel K, Wolfe CD, Busch MA, et al (2009). What are the social consequences of stroke for working-aged adults? A systematic review. Stroke 40:e431-440.

20) Dewey HM, Sherry LJ, Collier JM (2007). Stroke rehabilitation 2007: what should it be? Int J Stroke 2:191-200.

21) Fasotti L, Kovacs F, Eling PATM, et al (2000). Time pressure management as a compensatory strategy training after closed head injury. Neuropsychol Rehabil 10:47-65.

22) Ferro JM (2001). Hyperacute cognitive stroke syndromes. J Neurol 248:841-849. 
23) Folstein MF, Folstein SE, McHugh PR (1975). "Mini-mental state". A practical method for grading the cognitive state of patients for the clinician. J Psychiatry Res 12:189-198.

24) Gehring K, Sitskoorn MM, Gundy CM, et al (2009). Cognitive rehabilitation in patients with gliomas: a randomized, controlled trial. J Clin Oncol 27:3712-3722.

25) Gialanella B, Ferlucci C (2010). Functional outcome after stroke in patients with aphasia and neglect: assessment by the motor and cognitive functional independence measure instrument. Cerebrovasc Dis 30:440-447.

26) Giovagnoli AR, Del Pesce M, Mascheroni S, et al (1996). Trail making test: normative values from 287 normal adult controls. Ital J Neurol Sci 17:305-309.

27) Gollin D, Ferrari A, Peruzzi A (2011). Una palestra per la mente. Trento, Erickson ed.

28) Hachinski V, ladecola C, Petersen RC, et al (2006). National Institute of Neurological Disorders and StrokeCanadian Stroke Network vascular cognitive impairment harmonization standards. Stroke 37:2220-2241.

29) Hachinski V (2007). The 2005 Thomas Willis Lecture: stroke and vascular cognitive impairment: a transdisciplinary, translational and transactional approach. Stroke 38:1396.

30) Hamilton $M$ (1960). A rating scale for depression. J Neurol Neurosurg Psychiatry 23:56-62.

31) Hamilton BB, Granger CV, Sherwin FS, et al (1987). A uniform national data system for medical rehabilitation. In: Fuhrer MJ (Ed) Rehabilitation Outcomes: Analysis and Measurement. Baltimore, MD Brookes, pp 137-147.

32) Hoffmann M, Schmitt F, Bromley E (2009). Comprehensive cognitive neurological assessment in stroke. Acta Neurol Scand 119:162-171.

33) Hoffmann M (2001). Higher cortical function deficits after stroke: an analysis of 1,000 patients from a dedicated cognitive stroke registry. Neurorehabil Neural Repair 15:113-127.

34) Johansson BB (2011). Current trends in stroke rehabilitation. A review with focus on brain plasticity. Acta Neurol Scand 123:147-159.

35) Kim YH, Yoo WK, Ko MH, et al (2009). Plasticity of the attentional network after brain injury and cognitive rehabilitation. Neurorehabil Neural Repair 23:468-477.

36) Kwakkel G, Kollen B, Twisk J (2006). Impact of time on improvement of outcome after stroke. Stroke 37:2348-2353.

37) Làdavas $E$, Paolucci $S$, Umiltà $C$ (2011). Reasons for holding a Consensus Conference on neuropsychological rehabilitation in adult patients. Eur Phys Rehabil Med 47:91-99.

38) Loetscher T, Lincoln NB (2013). Cognitive rehabilitation for attention deficits following stroke. Cochrane Database Syst Rev 5:CD002842.

39) Luzzatti C, Willmes K, Dezlener R (1996). Aachener Aphasie Test (AAT). Florence, Organizzazioni Speciali

40) Nair RD, Lincoln NB (2007). Cognitive rehabilitation for memory deficits following stroke. Cochrane Database Syst Rev (3):CD002293.

41) Novelli G, Papagno C, Capitani E, et al (1986). Tre test clinici di ricerca e produzione lessicale: taratura su soggetti normali. Archivio di Psicologia, Neurologia e Psichiatria 47:477-486.

42) Nys GM, van Zandvoort MJ, de Kort PL, et al (2007). Cognitive disorders in acute stroke: prevalence and clinical determinants. Cerebrovasc Dis 23:408-416.

43) O'Brien AR, Chiaravalloti N, Goverover Y, et al (2008). Evidenced-based cognitive rehabilitation for persons with multiple sclerosis: a review of the literature. Arch Phys Med Rehabil 89:761-769.

44) Orsini A, Grossi D, Capitani E, et al (1987). Verbal and spatial immediate memory span: normative data from 1355 adults and 1112 children. Ital J Neurol Sci 8:539-548.
45) Owolabi MO (2010). What are the consistent predictors of generic and specific post-stroke health-related quality of life? Cerebrovasc Dis 29:105-110.

46) Paker N, Buğdaycı D, Tekdöş D, et al (2010). Impact of cognitive impairment on functional outcome in stroke. Stroke Res Treat doi: 10.4061/2010/652612.

47) Palop JJ, Chin J, Mucke L (2006). A network dysfunction perspective on neurodegenerative disease. Nature 443:768-773.

48) Paolucci S, Antonucci G, Gialloreti LE, et al (1996). Predicting stroke inpatient rehabilitation outcome: the prominent role of neuropsychological disorders. Eur Neurol 36:385-390.

49) Pasquini M, Leys $D$, Rousseaux M, et al (2007). Influence of cognitive impairment on the institutionalisation rate 3 years after a stroke. J Neurol Neurosurg Psychiatry 78:56-59.

50) Patel M, Coshall C, Rudd AG, et al (2003). Natural history of cognitive impairment after stroke and factors associated with its recovery. Clin Rehabil 17:158-166.

51) Petersen SE, van Mier H, Fiez JA, et al (1998). The effects of practice on the functional anatomy of task performance. Proc Natl Acad Sci USA 95:853-860.

52) Poulin V, Korner-Bitensky N, Dawson DR, et al (2012). Efficacy of executive function interventions after stroke: a systematic review. Top Stroke Rehabil 19:158-171.

53) Powell T, Malia K (2009). Training di riabilitazione cognitiva. Trento, Erickson ed.

54) Prokopenko SV, Mozheyko EY, Petrova MM, et al (2013). Correction of post-stroke cognitive impairments using computer programs. J Neurol Sci 325:148-153.

55) Quinn TJ, Paolucci S, Sunnerhagen KS, et al (2009). Evidence-based stroke rehabilitation: an expanded guidance document from the European Stroke Organisation (ESO) guidelines for management of ischaemic stroke and transient ischaemic attack 2008. J Rehabil Med 41:99-111.

56) Robertson I, Murre JM (1999). Rehabilitation of brain damage: brain plasticity and principles of guided recovery. Psychol Bull 125:544-575.

57) Serrano S, Domingo J, Rodríguez-Garcia E, et al (2007). Frequency of cognitive impairment without dementia in patients with stroke: a two-year follow-up study. Stroke 38:105-110.

58) Sohlberg MM, McLaughlin KA, Pavese A, et al (2000). Evaluation of attention process training and brain injury education in persons with acquired brain injury. $\mathrm{J}$ Clin Exp Neuropsychol 22:656-676.

59) Spinnler H, Tognoni G (1987). Standardizzazione e taratura italiana di test neuropsicologici. Ital J Neurol Sci 6 (Suppl 8).

60) Sturm W, Longoni F, Weis S, et al (2004). Functional reorganization in patients with right hemisphere stroke after training of alertness: a longitudinal PET and fMRI study in eight cases. Neuropsychologia 42:434.450.

61) Taylor GH, Broomfield NM (2013). Cognitive Assessment and Rehabilitation Pathway for Stroke (CARPS). Top Stroke Rehabil 20:270-282.

62) European Stroke Organisation (ESO) Executive Committee and the ESO; Writing Committee (2008). Guidelines for management of ischaemic stroke and transient ischaemic attack. Cerebrovasc Disc 25:457-507.

63) Wang H, Camicia M, Terdiman J, et al (2011). Time to inpatient rehabilitation hospital admission and functional outcomes of stroke patients. PM R 3:296-304.

64) Zucchella C, Capone A, Codella V, et al (2013). Cognitive rehabilitation for early post-surgery inpatients affected by primary brain tumor: a randomized, controlled trial. J Neurooncol 114:93-100. 